\title{
CARACTERIZAÇÃO DA ICTIOFAUNA E DA PESGA ARTESANAL NA PRAIA DO IGUAPE, AQUIRAZ - CEARÁ
}

\author{
Characterization of the ichthyofauna and artisanal \\ fishing at Iguape beach, Aquiraz - Ceará
}

\author{
Marcos Luiz da Silva Apoliano', Aldeney Andrade Soares Filho², Gabriel de Lima Asano³ \\ ${ }^{1}$ Mestre em Engenharia de Pesca, Universidade Federal do Ceará. E-mail: marcosapoliano@gmail.com \\ ${ }^{2}$ Professor adjunto IV do Departamento de Engenharia de Pesca, Universidade Federal do Ceará. \\ E-mail: icthybr@yahoo.com.br \\ ${ }^{3}$ Graduado em Engenharia de Pesca, Universidade Federal do Ceará. E-mail: gabrieldelimaasano7@gmail.com
}

\begin{abstract}
RESUMO
Localizado a $48 \mathrm{~km}$ da cidade de Fortaleza, o distrito de Iguape possui uma pequena praia frequentada por moradores da região, sendo reduto de pescadores que trabalham de forma artesanal e tiram da pesca o seu sustento. Visto a importância que essa atividade econômica tem para a população local, o objetivo desta pesquisa foi caracterizar a pesca artesanal, analisar a biodiversidade da ictiofauna e saber quais aquelas que são de importância econômica para a comunidade. Os resultados mostraram que são utilizadas embarcações do tipo jangadas e paquetes a vela e botes a remo em pescarias de "ir e vir" e de "dormir". As pescarias são realizadas com linha de mão, tarrafas e redes de espera. Foram capturados 2.655 espécimens, inseridos em duas classes, sete ordens, 18 famílias e 32 espécies, revelando uma elevada diversidade e riqueza de espécies, com destaque para Harengula clupeola, Opisthonema oglinum, Haemulon parra e Haemulon plumierii, que contribuem acentuadamente para a renda da comunidade pesqueira.
\end{abstract}

Palavras-chave: atividade econômica, peixe marinho, embarcações.

\section{ABSTRACT}

Located at $48 \mathrm{~km}$ from Fortaleza, the district of Iguape has a small beach frequented by residents of the region, it is a redoubt of artisanal fishermen that have the fishing as the main income. Considering the importance of this economic activity to the local population, the objective of this

Recebido em: 18/11/2019

Aprovado em: 21/1/2019

Publicado online em: 20/3/2020 
research was to characterize the artisanal fishery, to analyze the biodiversity of the fish fauna and to know which ones are of economic importance to the community. The fleet is composed by small wooden rafts that are hollow or filled with Styrofoam and driven by sail or paddle. The fishing activities last from some hours to 2 days. The fisheries are carried out with handlines, casting nets and gillnets. A total of 2.655 specimens were caught, belonging to 2 classes, 7 orders, 18 families and 32 species, revealing a high diversity and species richness, mainly from Harengula clupeola, Opisthonema oglinum, Haemulon parra and Haemulon plumieri, contributing significantly to the fishing community income.

Keywords: economic activity, marine fish, vessels.

\section{INTRODUÇÃO}

As regiões litorâneas e costeiras brasileiras apresentam ecossistemas extremamente produtivos no que diz respeito aos recursos naturais renováveis, nas quais existem diversas comunidades pesqueiras tradicionais que dependem desses recursos como fonte de renda e alimento. Esses recursos são obtidos por meio de atividades como a pesca artesanal (Diegues, 2001).

A atividade pesqueira é considerada uma das mais antigas exercidas pelo homem, proporcionando aos pescadores um vasto conhecimento sobre os recursos explorados. Responde por $54 \%$ do total dos desembarques de pescado provindo do ambiente marinho, o que torna evidente a grande importância desse segmento no Brasil (Diegues, 2001; Vasconcellos et al., 2011).

As praias arenosas constituem a maior parte das áreas costeiras do mundo, atuando como berçário para diversas espécies de peixes e crustáceos e oferecendo uma maior abundância de alimentos, além de proteção contra predadores. A fauna de peixes marinhos de águas costeiras arenosas é bastante rica, com condições climáticas diferentes, que se encontram ao longo de milhares de quilômetros de litoral, estuários e ilhas oceânicas (Araujo et al., 2008; Brown \& McLachlan, 1990; Gurgel et al., 2012).

No Brasil, vários estudos da ictiofauna foram realizados em áreas de praia, como na Praia de Jabaquara, Praia da Serraria, Praia da Fome e Praia do Bonete, em São Paulo (Ramires et al., 2012), Praia da Ilha do Frade, no Espírito Santo (Araujo et al., 2008), Praia de Viseu, no Pará (Santos et al., 2018), e Praia do Cassino, no Rio Grande do Sul (Pinheiro \& Vieira, 2009).

Embora vários estudos sobre a ictiofauna tenham sido realizados nas áreas praianas e suas proximidades no Nordeste (Araújo et al., 2000; Araújo et al., 2004; Basílio et al., 2009; Castro e Silva, 2004; Gurgel et al., 2014; Lessa \& Nóbrega, 2000; Mota Alves \& Soares-Filho, 1996; Nóbrega et al., 2009; Oliveira Silva et al., 2008; Osório et al., 2011), ainda há a necessidade de levantamentos da ictiofauna dessas regiões, como, por exemplo, na Praia do Iguape, uma vez que esses levantamentos visam enriquecer o conhecimento da sua biodiversidade, das relações ecológicas e principalmente para se compreender o grau de complexidade do ecossistema, assim como permitir novos estudos que auxiliem a preservação e o manejo desses locais.

Portanto, esta pesquisa teve por objetivo caracterizar a atividade pesqueira artesanal na Praia do Iguape, no Ceará, por meio da observação das embarcações e dos apetrechos 
utilizados, bem como caracterizar a ictiofauna e identificar as principais espécies com importância econômica para a comunidade.

\section{MATERIAL E MÉTODOS}

A pesquisa foi desenvolvida na Praia do Iguape (035' $\left.35^{\prime \prime} \mathrm{S}, 038^{\circ} 17^{\prime} 38^{\prime \prime} \mathrm{W}\right)$, que está localizada no município de Aquiraz, no Ceará, distante $48 \mathrm{~km}$ a sudeste de Fortaleza (Figura 1).

Foram realizadas coletas quinzenais, no período de junho de 2016 a junho de 2017, com um total de 26 coletas.

Figura 1 - Praia do Iguape, Aquiraz/CE. Fonte: adaptada do Google (2018).

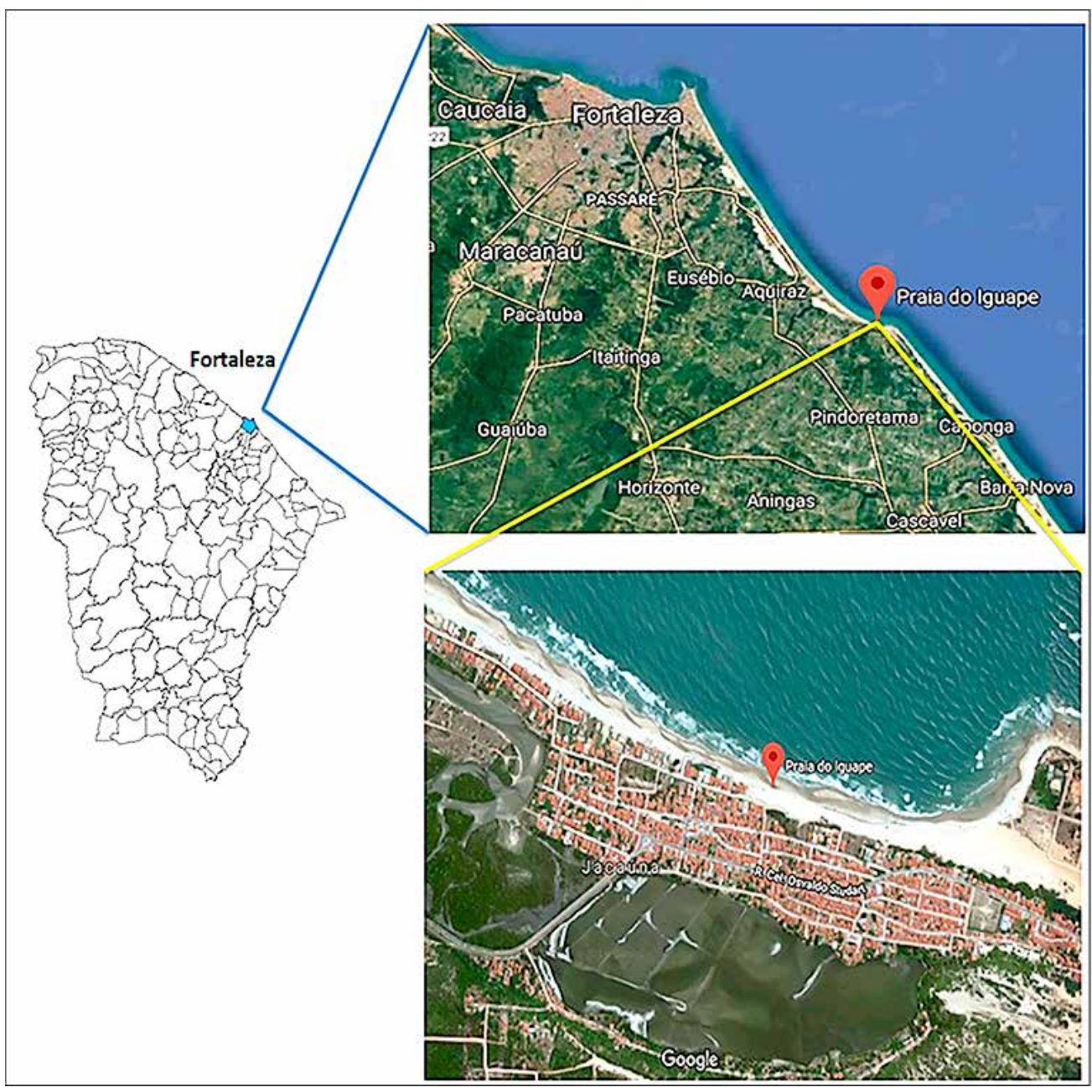

As embarcações foram identificadas e classificadas com base em informações segundo o Ibama (1997) e Araújo (1995). Também foram aplicados questionários estruturados aos pescadores a fim de obter informações sobre capacidade máxima de ocupantes, autonomia de mar, duração das pescarias e modo de armazenamento do pescado de cada embarcação identificada, as quais foram medidas com fita métrica para obtenção das medidas de comprimento, boca e pontal. 
Os dados da ictiofauna foram obtidos com as pescarias locais durante o desembarque dos peixes comercializados na praia. Os indivíduos capturados foram fotografados com câmera digital Sony Cyber-Shot DSC-W $350^{\circledR}, 14.1$ megapixels, e obtido o seu comprimento total. Foi visualizado o formato da sua linha lateral e, posteriormente, foi contado o número de espinhos e espículas dorsais, peitorais, pélvicas e anais.

A identificação das espécies foi realizada com base nos trabalhos de Cervigón et al. (1992), Nelson (2006), Nóbrega et al. (2009), Lessa e Nóbrega (2000), Rocha e Costa (2017) e em consultas ao site FishBase (2018) e a especialistas, nos quais foram comparadas as características morfológicas dos peixes com as espécies catalogadas e descritas na literatura.

As espécies foram classificadas com base na abundância relativa como: espécie dominante, aquela com abundância relativa $>50 \%$; espécie abundante, $>30 \% \leq 50 \%$; espécie moderadamente abundante, $>10 \% \leq 30 \%$; e espécie rara, $\leq 10 \%$ (Paranaguá, 1991).

Foram analisados três índices ecológicos: o índice de diversidade de espécie, o índice de riqueza de espécies de Margalef (d) e o índice de equabilidade de Pielou (J). O índice de diversidade de espécie foi avaliado segundo os índices de Shannon-Weaver $(\mathrm{H}$, em bits / indivíduo), Simpson (1/D) e Berger-Parker (1/d) (Magurran, 2007). O índice de riqueza de espécies de Margalef avalia o número de espécies presentes na amostra (Margalef, 1974), enquanto o índice de equabilidade de Pielou analisa a distribuição dos indivíduos entre as espécies (Odum, 2012).

\section{RESULTADOS E DISCUSSÃO}

As pescarias artesanais foram realizadas predominantemente durante cinco dias por semana, distribuídas em viagens de "ir e vir" (pescarias de menor duração, realizadas próximas à costa) e de "dormir" (pescarias com maior duração, geralmente de dois ou mais dias, realizadas em distâncias de até 30 milhas náuticas da costa).

Os resultados mostraram que a atividade pesqueira é realizada com as seguintes artes de pesca: linha e anzol, composta de: linha de poliamida (nylon) de 0,$1 ; 1,2 ; 1,4$ e 1,6 mm de diâmetro e anzol tamanho 2/0,4/0, 5/0, 6/0, 8/0 e 10/0; tarrafas lançadas ao longo da praia (Tabela I); e redes de espera (Tabela II).

Tabela I - Características das tarrafas utilizadas na captura da ictiofauna na Praia do Iguape, Aquiraz/CE

\begin{tabular}{cccc}
\hline $\begin{array}{c}\text { Altura } \\
(\mathbf{m})\end{array}$ & $\begin{array}{c}\text { Diâmetro } \\
(\mathbf{m})\end{array}$ & $\begin{array}{c}\text { Malha* } \\
(\mathbf{c m})\end{array}$ & $\begin{array}{c}\text { Nylon } \\
(\mathbf{m m})\end{array}$ \\
\hline 2,50 & 5,00 & 2,0 & 0,25 \\
3,00 & 6,00 & 2,5 & 0,25 \\
3,20 & 6,40 & 5,0 & 0,25 \\
\hline * Medida entre nós. & &
\end{tabular}

Tabela II - Características das redes de espera utilizadas na captura da ictiofauna na Praia do Iguape, Aquiraz/CE

\begin{tabular}{cccc}
\hline $\begin{array}{c}\text { Altura } \\
(\mathbf{m})\end{array}$ & $\begin{array}{c}\text { Comprimento } \\
(\mathbf{m})\end{array}$ & $\begin{array}{c}\text { Malha* }^{*} \\
(\mathbf{c m})\end{array}$ & $\begin{array}{c}\text { Nylon } \\
(\mathbf{m m})\end{array}$ \\
\hline 1,50 & 150,0 & 3,0 & 0,20 \\
2,50 & 500,0 & 5,0 & 0,25 \\
\hline
\end{tabular}

* Medida entre nós. 
Ao analisar as embarcações utilizadas na Praia do Iguape, foi observado o uso de jangada (ocada), de paquete (ocado ou forrado com isopor), ambas a vela, e de bote a remo (Figura 2).

Figura 2 - Embarcações utilizadas na Praia do Iguape, Aquiraz/CE. Nota: (a) jangada a vela, (b) paquete a vela, (c) bote a remo

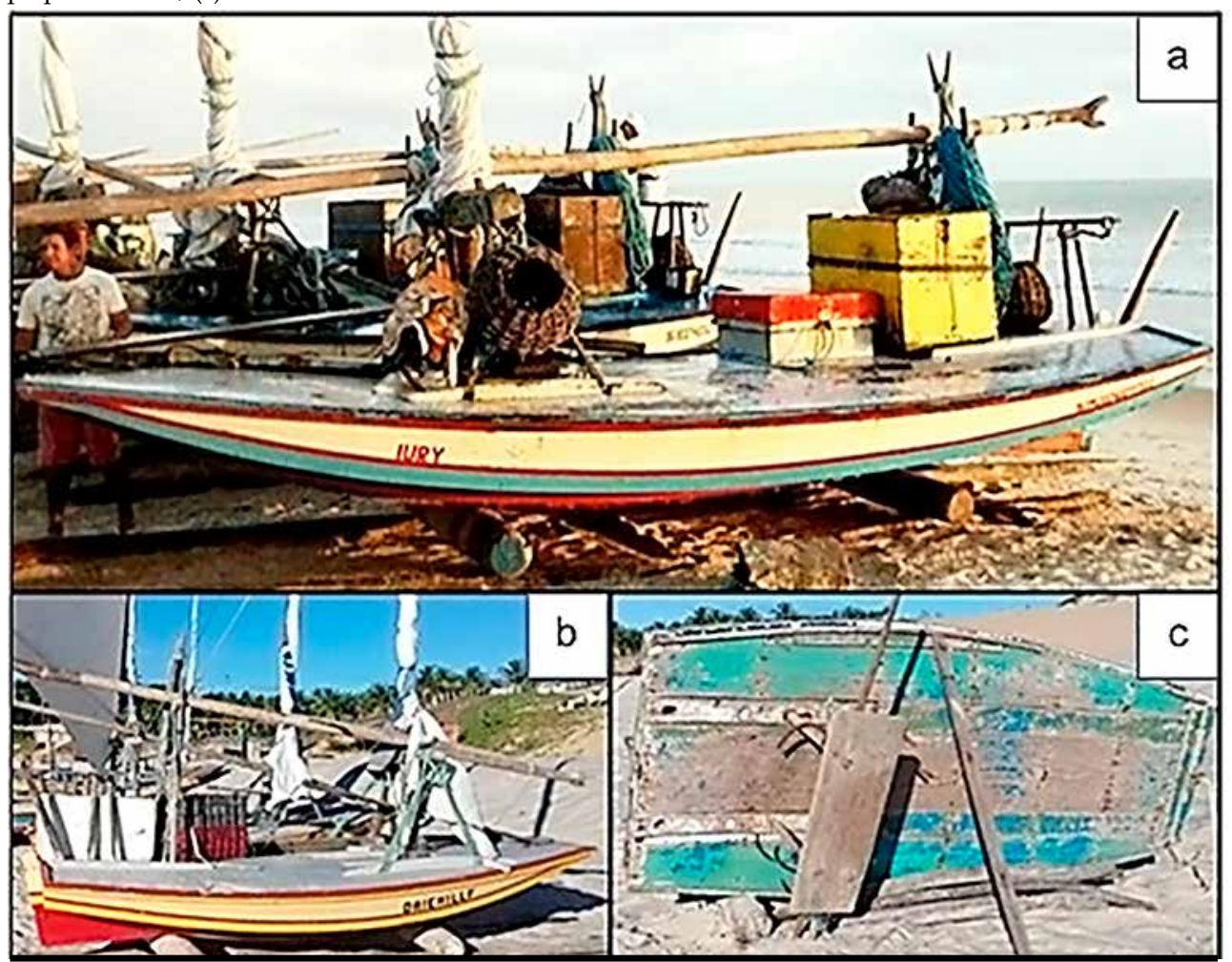

As jangadas encontradas na Praia do Iguape possuem comprimento entre 6,0 e 7,5 m, com boca média de 2,3 $\pm 0,15 \mathrm{~m}$ e pontal médio de $0,65 \pm 0,07 \mathrm{~m}$, são capazes de comportar de quatro a cinco pescadores, possuem porão acessível por uma escotilha (abertura para entrada, em formato de caixa, na embarcação), servindo de abrigo e dormitório para os pescadores, e possuem ainda caixas isotérmicas para armazenamento do pescado.

Os resultados obtidos se assemelham aos descritos pelo Ibama (1998), que descreve as embarcações do tipo jangadas ocadas como sendo movidas a vela, construídas de madeira, com casco chato, desprovidas de quilha e com comprimento maior ou igual a 5,90 m, tendo pontal e boca maiores que as embarcações classificadas como paquetes.

As jangadas de tábua são tradicionalmente ocadas, ou seja, têm porão. Elas são descritas por Araújo (1995) como dotadas de escotilha, uma abertura retangular sobre o convés, com tampa em forma de caixa, através da qual se atinge o porão, onde são guardados os utensílios para pesca de quatro a cinco dias em alto mar.

Os paquetes vistos na Praia do Iguape medem de 3,5 a 5,48 m de comprimento, são capazes de comportar de um a três pescadores, não possuem porão, mantêm o pescado fresco em estruturas chamadas de "samburá" e são utilizados em pesca de "ir e vir", características essas que também conferem com as descritas pelo Ibama (1997), que define as embarcações movidas a vela, construídas de madeira, sem quilha e tendo casco chato e normalmente revestido internamente de isopor (paquete de isopor), cujo tamanho varia entre 2,0 e 5,89 m de comprimento. 
Com a mesma forma das jangadas, os paquetes ocados são similarmente construídos com estrutura estanque, tendo espaço interno para acomodação e alocação de pequenos objetos. Possuem como distinção principal o menor tamanho, sendo capazes de comportar uma tripulação de dois ou três pescadores, viajando em sistemas de "ir e vir" e "dormir".

Os botes a remo observados na Praia do Iguape possuem características semelhantes aos paquetes de isopor. Também são embarcações construídas de madeira, sem quilha, com casco chato e revestido internamente de isopor. Porém, os botes são menores, medem entre 2,5 e 3,0 m, comportam de um a dois pescadores e são utilizados na pescaria realizada próximo à costa, de modo a visualizar a praia.

Com relação aos peixes, foram capturados 2.655 exemplares, distribuídos entre 32 espécies diferentes, as quais estão agrupadas em sete ordens, 18 famílias e duas classes. Araújo et al. (2000) também fizeram um estudo semelhante ao presente trabalho, no qual foram observadas as espécies de peixes que ocorrem na região entre marés na costa do estado do Ceará, capturando 77 espécies, pertencentes a 59 gêneros e 35 famílias, evidenciando uma alta variedade de espécies notadas também em pesquisas realizadas por Godefroid et al. (2003), que analisaram a ictiofauna na zona de arrebentação do balneário da Praia de Atami, sendo capturados 9.446 peixes de 24 famílias e 72 espécies diferentes, quantidade de espécies bem superior a deste trabalho.

Na zona de arrebentação de praias arenosas do estado de São Paulo, Giannini e Paiva Filho (1995) fizeram uma análise comparativa da ictiofauna local, sendo capturados 54.384 indivíduos inseridos em 99 espécies pertencentes a 40 famílias no litoral sul, 67 espécies agrupadas em 31 famílias no litoral central e 52 espécies agrupadas em 25 famílias no litoral norte, valores maiores aos encontrados na Praia do Iguape.

Quanto à participação relativa das ordens e ao número de espécies, a ordem que englobou a maior quantidade de espécies foi a Perciformes, com 24 (75\%), seguida de Clupeiformes e Siluriformes, com duas (6,25\%) cada, e ainda Mugiliformes, Beryciformes, Carcharhiniformes e Myliobatiformes, com uma (3,12\%) cada (Figura 3).

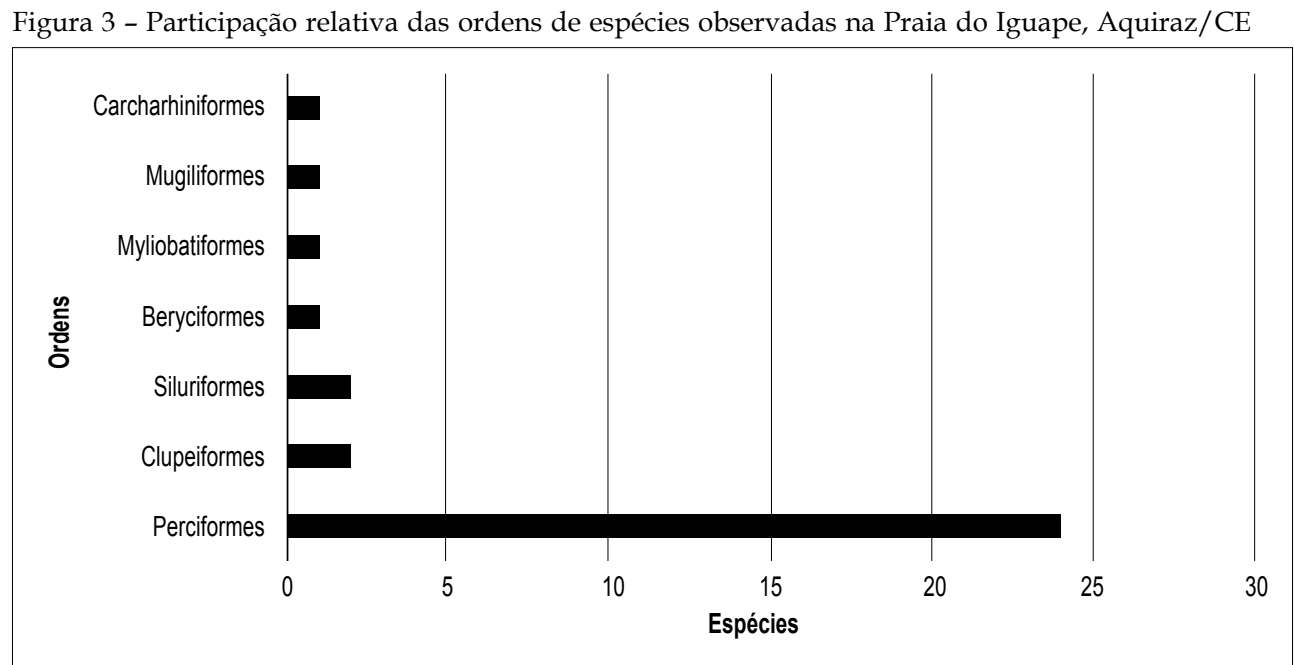

Registrou-se no presente trabalho a ocorrência de peixes que também foram contemplados nas pesquisas de Gurgel et al. (2012) realizadas na Praia de Ponta Negra, no Rio Grande do Norte, onde foram registradas 10 espécies de peixes, distribuídos em três or- 
dens (Carcharhiniformes, Siluriformes e Perciformes), em que a ordem Perciformes também teve maior representatividade, com seis famílias (Centropomidae, Carangidae, Sciaenidae, Ephippidae, Scombridae e Trichiuridae).

As famílias que mais se destacaram em números de indivíduos foram: Clupeidae, com 1.079 (40,64\%); Haemulidae, com 620 (23,35\%); Malacanthidae, com 267 (10,06\%); Lutjanidae, com 139 (5,23\%); Scombridae, com 131 (4,93\%); Carangidae, com 102 (3,84\%); Holocentridae, com 69 (2,59\%); Ariidae, com 48 (1,81\%); Serranidae, com 40 (1,51\%), e as famílias Echeneidae, Polynemidae, Centropomidae, Trichiuridae, Gerreidae, Labridae, Mugilidae, Triakidae e Dasyatidae, com 160 (6,03\%) (Figura 4).

Figura 4 - Percentual de famílias de espécies pescadas na Praia do Iguape, Aquiraz/CE, com relação ao número de indivíduos

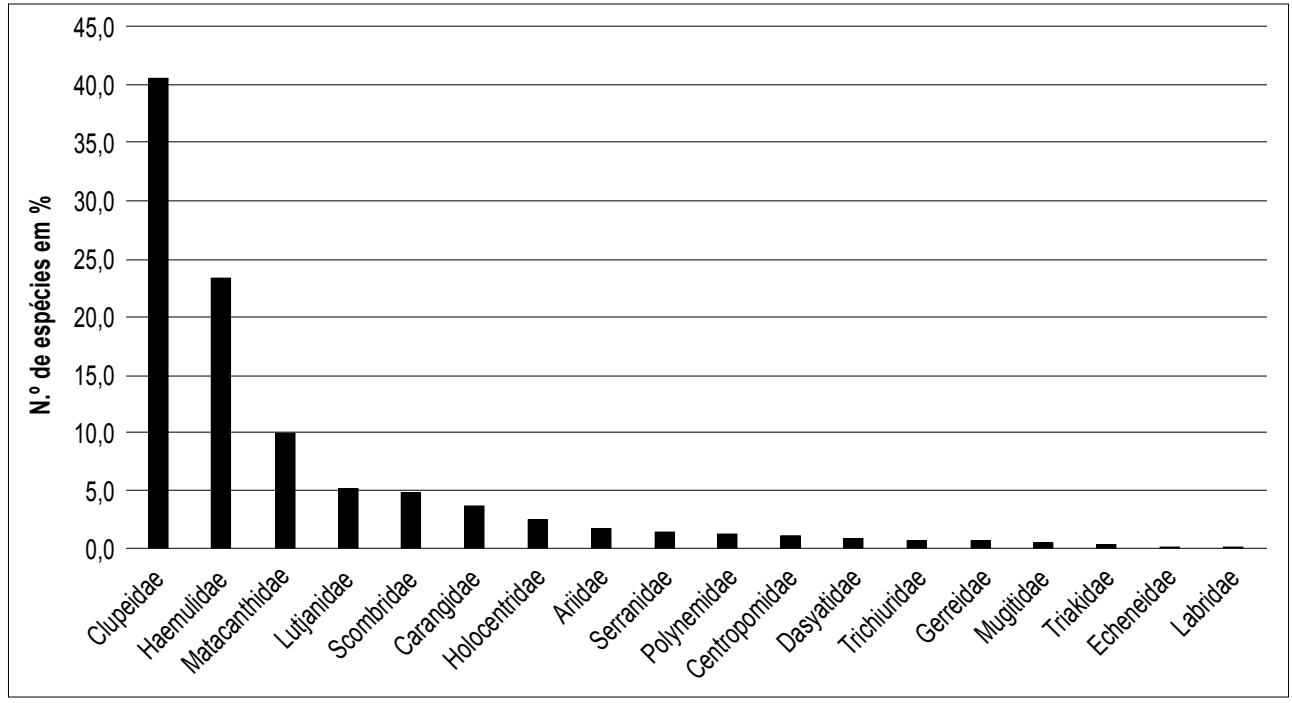

O resultado divergiu do levantamento da ictiofauna no estuário do Rio Curu feito por Basilio (2008), no qual as famílias com maior número de espécies foram Gerreidae, Mugilidae, Engraulidae, Gobidae, Lutijanidae e Carangidae, evidenciando a diversidade dos dois ambientes.

De acordo com a Tabela III, as espécies de peixes da Praia do Iguape foram classificadas como: abundantes (abundância relativa $>30 \leq 50 \%$ ), moderadamente abundantes (abundância relativa $>10 \leq 30 \%$ ) e raras (abundância relativa $\leq 10 \%$ ).

Tabela III - Abundância relativa da ictiofauna capturada na Praia do Iguape, Aquiraz/CE

\begin{tabular}{|l|c|c|c|}
\hline \multicolumn{1}{|c|}{ Espécies } & $\begin{array}{c}\text { Total de } \\
\text { Indivíduos } \\
\text { Capturados }\end{array}$ & $\begin{array}{c}\text { Abundância } \\
\text { Relativa (\%) }\end{array}$ & Classificação \\
\hline Harengula clupeola (Cuvier, 1829) & 804 & 30,28 & Abundante \\
\hline Opisthonema oglinum (Lesueur, 1818) & 275 & 10,36 & $\begin{array}{c}\text { Moderadamente } \\
\text { abundante }\end{array}$ \\
\hline Haemulon parra (Desmarest, 1823) & 274 & 10,32 & $\begin{array}{c}\text { Moderadamente } \\
\text { abundante }\end{array}$ \\
\hline Haemulon plumierI (Lacepède, 1801) & 267 & 10,06 & $\begin{array}{c}\text { Moderadamente } \\
\text { abundante }\end{array}$ \\
\hline Malacanthus plumieri (Bloch, 1786) & 266 & 10,02 & $\begin{array}{c}\text { Moderadamente } \\
\text { abundante }\end{array}$ \\
\hline
\end{tabular}


(continuação Tabela 1)

\begin{tabular}{|l|c|c|c|}
\hline \multicolumn{1}{|c|}{ Espécies } & $\begin{array}{c}\text { Total de } \\
\text { Indivíduos } \\
\text { Capturados }\end{array}$ & $\begin{array}{c}\text { Abundância } \\
\text { Relativa (\%) }\end{array}$ & Classificação \\
\hline Scomberomorus brasiliensis (Zavala-Camin, 1978) & 105 & 3,95 & Rara \\
\hline Ocyurus chrysurus (Bloch, 1791) & 99 & 3,73 & Rara \\
\hline Holocentrus adscensions (Osbeck, 1765) & 69 & 2,60 & Rara \\
\hline Lutjanus buccanella (Cuvier, 1828) & 40 & 1,51 & Rara \\
\hline Cephalopholis fulva (Linnaeus, 1758) & 40 & 1,51 & Rara \\
\hline Chloroscombrus chrysurus (Linnaeus, 1766) & 36 & 1,36 & Rara \\
\hline Polydactylus virginicus (Linnaeus, 1758) & 34 & 1,28 & Rara \\
\hline Centropomus ensiferus (Poey, 1860) & 32 & 1,21 & Rara \\
\hline Haemulopsis corvinaeformis (Steindachner, 1868) & 30 & 1,13 & Rara \\
\hline Conodon nobilis (Linnaeus, 1758) & 27 & 1,02 & Rara \\
\hline Auxis thazard (Lacepède, 1800) & 26 & 0,98 & Rara \\
\hline Genidens genidens (Cuvier, 1829) & 26 & 0,98 & Rara \\
\hline Dasyatis guttata (Springer, 1939) & 26 & 0,98 & Rara \\
\hline Selene setapinnis (Mitchill, 1815) & 23 & 0,87 & Rara \\
\hline Aspistor luniscutis (Valenciennes, 1840) & 22 & 0,83 & Rara \\
\hline Trichiurus lepturus (Linnaeus, 1758) & 19 & 0,72 & Rara \\
\hline Eugerres brasilianus (Cuvier, 1830) & 18 & 0,68 & Rara \\
\hline Mugil curema (Valenciennes, 1836) & 17 & 0,64 & Rara \\
\hline Seriola rivoliana (Valenciennes, 1833) & 15 & 0,56 & Rara \\
\hline Selar crumenophthalmus (Bloch, 1793) & 15 & 0,56 & Rara \\
\hline Haemulon steindachneri (Gilbert, 1882) & 12 & 0,45 & Rara \\
\hline Anisotremus surinamesis (Bloch, 1791) & 3 & 0,41 & Rara \\
\hline Caranx latus (Agassiz, 1831) & 2 & 0,38 & Rara \\
\hline Mustelus schmitti (Springer, 1939) & & 0,30 & Rara \\
\hline Echenesis naucrates (Linnaeus, 1758) & 0,15 & Rara \\
\hline Oligoplites saurus (Schneider, 1801) & 0,11 & \\
\hline Halichoeres cyanocephalus (Bloch, 1791) & 0,08 & Rara \\
\hline
\end{tabular}

Entre as espécies capturadas, apenas a sardinha-cascuda (Harengula clupeola) foi considerada abundante, com abundância relativa de 30,28\%, enquanto a sardinha-bandeira (Opistonema oglinum), o biquara (Haemulon parra), o sapuruna (Haemulon plumierI) e o pirá (Malacanthus plumieri) foram moderadamente abundantes, com abundância relativa igual a 10,36\%,10,32\%,10,06\% e 10,02\% respectivamente. Essas são as espécies com maior importância econômica para a comunidade pesqueira na Praia do Iguape (Figura 5).

Segundo os pescadores locais, sazonalmente ocorrem espécies como: pampo, pacamon e carapitanga. Mas não foi observada nenhuma captura desses espécimes pelos pescadores durante o período de estudo. Para Longino et al. (2002), as espécies não são fáceis de amostrar, pois a probabilidade de captura não está unicamente relacionada com sua abundância, o que pode causar um erro nos estudos de diversidade biológica.

No geral, a abundância de uma espécie está relacionada ao seu sucesso na competição por recursos limitados em um ambiente. Não existe ecossistema em que as espécies apresentem abundância perfeitamente uniforme. O que ocorre normalmente é a presença de alguma espécie com grande abundância, outras moderadamente e as demais são consideradas raras. Em alguns casos, apenas uma ou duas espécies dominam, com as restantes sendo pouco frequentes ou raras. Em outras situações, a abundância das espécies é mais uniforme, porém jamais perfeitamente (Magurran, 2007). 


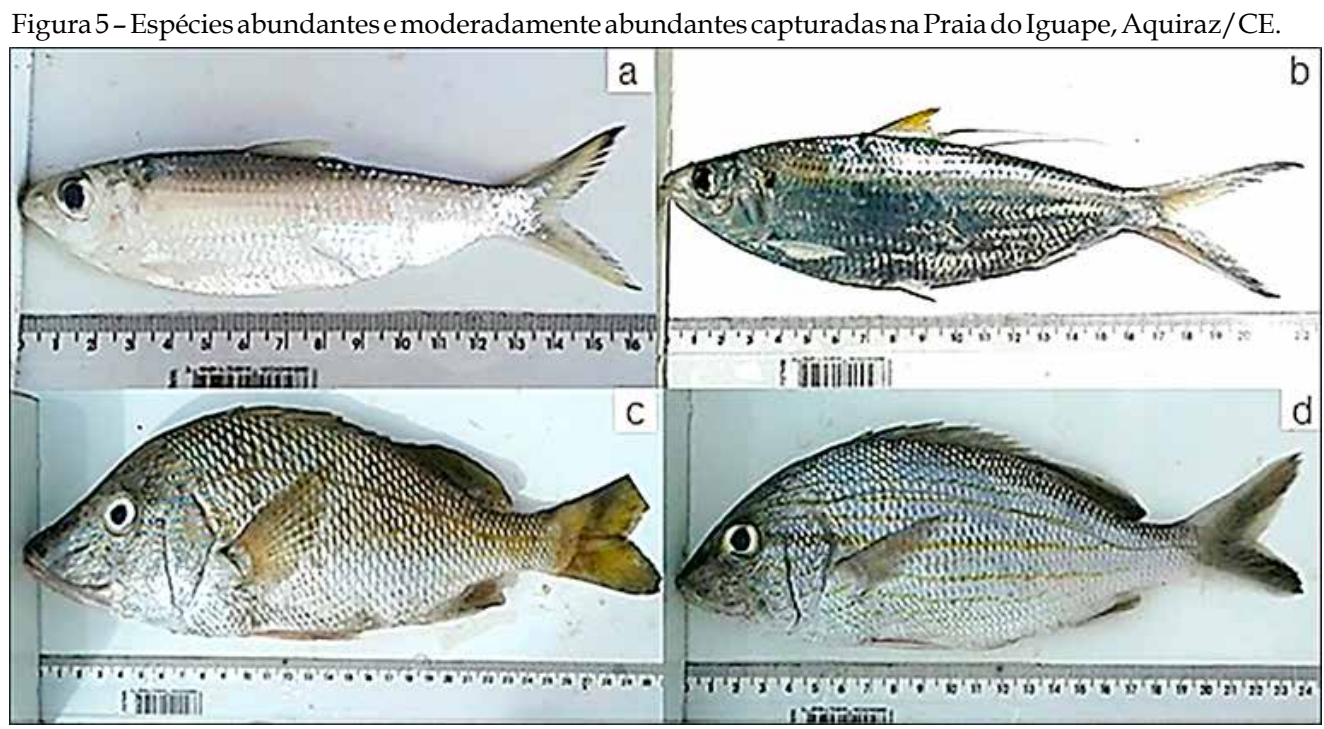

Nota: (a) Harengula clupeola, (b) Opistonema oglinum, (c) Haemulon parra, (d) Haemulon plumierrii.

Quanto à importância econômica das espécies capturadas pela pesca artesanal na Praia do Iguape, foi observada a predominância de sardinha-cascuda (Harengula clupeola), sardinha-bandeira (Opistonema oglinum), biquara (Haemulon parra), sapuruna (Haemulon plumieri) e pirá (Malacanthus plumieri), o que evidencia uma ampla variedade de espécies que contribuem para a economia local. Pesquisas semelhantes foram realizadas por Osório et al. (2011), os quais estudaram a ictiofauna do estuário do Rio Pacoti, no Ceará, e identificaram que as espécies Lutjanus alexandrei, Lutjanus jocu e Bathygobius soporator apresentaram maior frequência de ocorrência, com $48 \%, 17 \%$ e $15 \%$, respectivamente.

Embora a pesca da Harengula clupeola e Opisthonema oglinum seja evidenciada apenas entre os meses de agosto e dezembro, essas espécies possuíram a maior produtividade, com média de 220 e $180 \mathrm{~kg}$, respectivamente, sendo comercializadas a R\$ 6,00 o quilo.

As demais espécies (Haemulon parra, Haemulon plumieri e Malacanthus plumieri) são evidenciadas durante todo ano e também apresentam uma boa produtividade, com produção mensal de 150, 140 e 120 kg, respectivamente. Todas essas espécies são comercializadas a um valor de R\$10,00 o quilo. Já as demais espécies foram consideradas raras, com abundância relativa $<10 \%$.

Quanto aos índices de diversidade de espécies no período seco, que compreende os meses de junho a novembro, verificou-se na Praia do Iguape que o índice de diversidade de Shannon-Weaver apresentou um valor de 3,26 bits/inds., o de Simpson foi de 4,65 e Berger-Parker de 2,40, os quais podem ser considerados elevados. No período chuvoso, que compreende os meses de dezembro a maio, o índice de diversidade de ShannonWeaver apresentou um valor de 3,24 bits/inds., o de Simpson foi de 9,55 e o de BergerParker de 5,74, índices considerados elevados para o período.

O valor numérico da diversidade de Shannon-Weaver é influenciado pelo número de espécies (riqueza de espécies) e pela regularidade na qual os indivíduos estão distribuídos entre as diferentes espécies (equabilidade), que normalmente varia entre 1,0 e 3,5 para as populações de peixes (Margalef, 1974). Portanto, os valores obtidos nesta pesquisa mostram uma diversidade de espécies bastante elevada. Segundo Magurran (2007) e Odum (2012), enquanto o índice de Shannon atribui um peso maior às espécies raras e o de 
Simpson, às espécies comuns, o índice de Berger-Parker se baseia na abundância máxima observada entre as espécies e na abundância total, expressando, assim, a abundância proporcional das espécies mais abundantes, sendo considerado entre os índices disponíveis aquele que mede de forma mais satisfatória a diversidade das espécies.

Em relação aos índices de riqueza de espécies de Margalef (d) e equabilidade de Pielou no presente trabalho, foi observado que durante o período chuvoso a riqueza de espécies (d) foi de 6,33 e no período de junho a novembro apresentou um valor de 5,51. Margalef (1974) define a diversidade de espécies como uma função do número de espécies presentes em uma comunidade e a equabilidade como a proporção de indivíduos entre as espécies que compõem a fauna marinha. Quanto à equabilidade, o valor foi igual a 0,66 para o período chuvoso, enquanto no seco esse valor foi de 0,61 , indicando, assim, uma boa distribuição dos indivíduos entre as espécies. Esse índice varia de zero, para a diversidade mínima, a 1,0 quando a diversidade é máxima, considerando-se os valores superiores a 0,50 como significantes (Odum, 2012).

\section{CONCLUSÃO}

Com o presente trabalho foi possível concluir que a pesca artesanal na Praia do Iguape é realizada com jangada e paquete a vela e com bote a remo em pescarias de "ir e vir" e de "dormir", utilizando linha e anzol, tarrafas lançadas ao longo da praia e rede de espera como arte de pesca.

Em relação à ictiofauna, a ordem Perciformes foi a mais representativa, com 24 espécies, sendo Harengula clupeola a mais expressiva em número de indivíduos amostrados, e considerada abundante, seguida de Opisthonema oglinum, Haemulon parra, Haemulon plumieri e Malacanthus plumieri, que foram consideradas moderadamente abundantes, no entanto contribuindo acentuadamente para a renda da comunidade pesqueira na Praia do Iguape.

O estudo da ictiofauna na Praia do Iguape revelou uma variação na abundância das espécies em que a produção de algumas se sobressai, contribuindo de forma significativa para a economia local. Apesar disso, carece de um acompanhamento anual que verifique outros fatores que possam influenciar essa abundância, como estudos da produtividade primária, correntes oceânicas e de parâmetros ambientais.

\section{REFERÊNCIAS BIBLIOGRÁFICAS}

Araujo, C.C.V.; Rosa, D.M.; Fernades, J.M.; Ripoli, L.V. \& Krohling, W. Composição e estrutura da comunidade de peixes de uma praia arenosa da Ilha do Frade, Vitória, Espírito Santo. Iheringia, Sér. Zool., Porto Alegre, v. 1, n. 98, p. 129-135, 2008.

Araújo, M.E.; Teixeira, J.M.C. \& Oliveira, A.M.E. Ictiofauna marinha do estado do Ceará, Brasil: III. Actinopterygii de estuários. Arq. Ciênc. Mar, Fortaleza, v. 33, p. 139-142, 2000.

Araújo, M.E.; Teixeira, J.M.C. \& Oliveira, A.M.E. Peixes estuarinos marinhos do Nordeste brasileiro: guia ilustrado. Fortaleza, Edições UFC, 2004.

Araújo, N.B.G. Jangadas. Editora Banco do Nordeste do Brasil, Fortaleza, 64 p., 1995.

Basilio, T.H. A pesca e os pescadores artesanais do estuário do Rio Curu - Ceará - Brasil. Monografia de graduação, curso de Engenharia de Pesca, Centro de Ciências Agrárias, Universidade Federal do Ceará, 59 p., Fortaleza, 2008. 
Basilio, T.H.; Godinho, W.O.; Araújo, M.E.; Furtado-Neto, M.A.A. \& Faria, V.V. Ictiofauna do estuário do Rio Curu, Ceará, Brasil. Arq. Ciênc. Mar, v. 42, n. 2, p. 81-88, 2009.

Brown, A.C. \& McLachlan, A. Ecology of sandy shores. Elsevier, 328 p., New York, 1990.

Castro e Silva, S.M.M. Caracterização da pesca artesanal na costa do estado do Ceará, Brasil. 2004. 262 f. Tese de doutorado, Programa de Pós-Graduação em Ecologia e Recursos Naturais, Universidade Federal de São Carlos, 262 p., São Paulo, 2004.

Cervigón, F.R.; Cipriani, W.; Fischer, L.; Garibaldi, M.; Hendrickx, A.J.; Márquez, R.; Poutiers, L.M.; Robaina, G. \& Rodriguez, B. Guía de campo de las especies comerciales marinas y de aquas salobres de la costa septentrional de Sul América. FAO, 513 p., Roma, 1992.

Diegues, A.C.S. Ecologia humana e planejamento costeiro. Edusp, 225 p., São Paulo, 2001.

FishBase. FishBase. 2018. Disponível em: http://www.fishbase.org/search.php. Acesso em: 4 abr. 2018.

Giannini, R. \& Paiva Filho, A.M. Análise comparativa da ictiofauna da zona de arrebentação de praias arenosas do estado de São Paulo, Brasil. Bol. Inst. Oceanogr., São Paulo, v. 43, p.141-152, 1995.

Godefroid, R.S.; Spach, H.L.; Schwarz, R.J. \& Mac Laren, G.Q. A fauna de peixes da praia do Balneário Atami, Paraná, Brasil. Revista Atlântica, Rio Grande, v. 25, p. 147-161, 2003.

Google. Google Earth. 2018. Disponível em: https://www.google.com.br/intl/pt-BR/earth/. Acesso em: 22 abr. 2018.

Gurgel, T.A.B.; Carvalho, M.M.; Oliveira, M.R. \& Chellappa, S. Ocorrência e caracterização de peixes marinhos da praia de Ponta Negra, Rio Grande do Norte, Brasil. Biota Amazônica, Macapá, v. 4, n. 3, p. 112-118, 2014.

Gurgel, T.A.B.; Oliveira, M.R.; Brasil, D.F. \& Chellappa, S. Peixes marinhos das águas costeiras da praia de Ponta Negra, Natal, Rio Grande do Norte. Biota Amazônia, v. 2, n. 1, p. 83-97, 2012.

Ibama. Boletim estatístico da pesca marítima e estuarina do estado do Ceará - 1996. Centro de Pesquisa e Gestão de Recursos Pesqueiros do Litoral Nordeste. 65 p.,Tamandaré, 1997.

Ibama. Boletim estatístico da pesca marítima e estuarina do estado do Ceará - 1997. Centro de Pesquisa e Gestão de Recursos Pesqueiros do Litoral Nordeste. 72

p., Tamandaré, 1998.

Lessa, R. \& Nóbrega, M.F. Guia de identificação de peixes marinhos da região Nordeste, Programa Revizee - Score-NE. Recife, 2000. Disponível em: http:/ / www.mma.gov.br/estruturas/revizee/_arquivos/guiaiden.pdf. Acesso em: 16 nov. 2017.

Longino, J.T.; Coddington, J. \& Colweell, R.K. Theant fauna of a tropical rain forest: estimating species richness three different ways. Ecology, Washington, v. 83, p. 689-702, 2002.

Magurran, A.E. Measuring biological diversity. Ed. Blackwell Science, 256 p., New Jersey, 2007. Margalef, R. Ecología. Omega, 951 p., Barcelona, 1974.

Mota Alves, M.I. \& Soares-Filho, A.A. Peixes do estuário do Rio Jaguaribe (Ceará-Brasil): aspectos fisioecológicos. Ciên. Agron., v. 27, n. 1, p. 5-16, 1996.

Nelson, J.S. Fishes of the world. Ed. John Wiley \& Sons, 601 p., New York, 2006. 
Nóbrega, M.F.; Lessa, R. \& Santana, F.M. Peixes marinhos da região Nordeste do Brasil: Programa Revizee. Martins \& Cordeiro, 208 p., Fortaleza, 2009.

Odum, E.P. Ecologia. Guanabara Koogan, 434 p., Rio de Janeiro, 2012.

Oliveira Silva, J.T; Peso Aguiar, M.C. \& Lopes, P.R.D. Ictiofauna das praias de Cabuçu e Berlinque: uma contribuição ao conhecimento das comunidades de peixes na Baía de Todos os Santos - Bahia, Brasil. Biotemas, Florianópolis, v. 21, n. 4, p. 105-115, 2008.

Osório, F.M.; Godinho, W.O. \& Lotufo, T.M.C. Ictiofauna associada às raízes de mangue do estuário do Rio Pacoti - CE, Brasil. Biota Neotropica, São Paulo, v. 11, n. 1, p. 415-420, 2011.

Paranaguá, M.N. Cladocera (Crustacea) do estuário do Rio Capibaribe - Recife - Pernambuco. Tese de doutorado, Programa de Pós-Graduação em Zoologia, Universidade Federal Rural de Pernambuco, 102 p., Recife, 1991.

Pinheiro, M.S.L. \& Vieira, J.P.V. Variação espaço-temporal da ictiofauna da zona de arrebentação da Praia do Cassino, Rio Grande do Sul, Brasil. Zoologia, Curitiba, v. 26, n. 3, p. 499-510, 2009.

Ramires, M.; Clauzet, M.; Rotundo, M.M. \& Bergossi, A. A pesca e os pescadores artesanais de Ilhabela (SP), Brasil. Bol. Inst. Pesca, São Paulo, v. 38, n. 3, p. 231-246, 2012.

Rocha, L.O.F. \& Costa, P.A.S. Manual de identificação de peixes marinhos para a Costa Central, Programa Revizee - Score Central. Disponível em: http://www.mma.gov.br/. Acesso em: 17 nov. 2017.

Santos, R.F.; Monteiro, E.P.; Nascimento, J.C.S. \& Santos, W.J.P. A pesca artesanal no nordeste paraense, município de Viseu - Pará. Acta of Fisheries and Aquatic Resources, Sergipe, v. 6, n. 1, p. 35-43, 2018.

Vasconcellos, M.; Diegues, A.C. \& Kalikoski, D.C. Coastal fisheries of Brazil. p. 73-117, in Salas, S.; Chuenpagdee, R.; Charles, A. \& Seijo, J.C. (eds.), Coastal fsheries of Latin America and the Caribbean. FAO Fisheries and Aquaculture Technical Paper, 544 p., Rome, 2011. 